\title{
Jurnal Bimbingan Konseling
}

http://journal.unnes.ac.id/sju/index.php/jubk

\section{PENGEMBANGAN MODEL BIMBINGAN KELOMPOK DENGAN TEKNIK MIND MAPPING UNTUK MENGEMBANGKAN KREATIVITAS SISWA}

\author{
Fitri Wahyuni
}

Prodi Bimbingan Konseling, Program Pascasarjana, Universitas Negeri Semarang, Indonesia

\section{Info Artikel}

Sejarah Artikel:

Diterima Oktober 2013

Disetujui Oktober 2013

Dipublikasikan November 2013

\section{Keywords:}

Creativity;

Group guidance;

Mind mapping technique

\begin{abstract}
$\underline{\text { Abstrak }}$
Setiap siswa pada hakikatnya kreatif. Untuk mengembangkan potensi kreatif siswa diperlukan lingkungan yang dapat memfasilitasi perkembangan potensi kreatif. Salah satu layanan bimbingan dan konseling yang efektif untuk mengembangkan kreativitas siswa adalah layanan bimbingan kelompok. Penelitian ini bertujuan untuk menghasilkan model bimbingan kelompok dengan teknik mind mapping untuk mengembangkan kreativitas siswa SMP N 2 Semarang. Penelitian ini menggunakan metode Penelitian dan Pengembangan Pendidikan (Educational Research and Development). Hasil implementasi model menunjukkan bahwa model bimbingan kelompok dengan teknik mind mapping terbukti efektif mengembangkan kreativitas siswa. Tingkat kreativitas siswa mengalami kenaikan sebesar 8,2\% dari sebelumnya $66,1 \%$ meningkat menjadi $74,3 \%$. Peningkatan tersebut terjadi pada semua aspek kreativitas. Hasil uji statistik wicoxon menunjukkan nilai probabilitas dibawah $0,05(0,0025<0,05)$, artinya bahwa bimbingan kelompok teknik mind mapping efektif untuk mengembangkan kreativitas siswa. Disarankan bagi guru khususnya guru bimbingan dan konseling untuk selalu meningkatkan kualitas layanan bimbingan dan konseling, dan model bimbingan kelompok dengan teknik mind mapping yang dikembangkan dalam penelitian ini hendaknya dapat digunakan konselor sebagai salah satu model layanan dalam membantu siswa SMP untuk mengembangkan kreativitas siswa.
\end{abstract}

\begin{abstract}
$\underline{\text { Abstract }}$
Each student is essentially creative. In order to construct student creative potency required an environment wich facilitating the development of creative potency. One of guidance and counseling effective service to develop creativity is group guidance services. The aim of this research is to generate an effective mind mapping tecnique group guidance model to improve students' creativity. This study uses a model of educational research and development. The results showed that mind mapping technique group guidance model is effective to improve students' creativity. Level of students' creativity increased creativity about $8.2 \%$ before group guidance is $66 \%$ and $74.3 \%$ after group guidance. It increased of level of occurred in all aspects of creativity. The results from test statistic wilcoxon that skor of probability under 0.05 $(0,0025<0,05)$, so mind mapping technique group guidance model is effective to improve students' creativity. Suggestions: forteachers, especially guidance and counseling teachers always improve the quality of guidance and counseling services, and mindmapping technique group guidance model developed in this research should be used by counselor as a model services to helping junior high school students to enhance their creativity.
\end{abstract}

(C) 2013 Universitas Negeri Semarang

\footnotetext{
$\bowtie$ Alamat korespondensi:

Kampus Unnes Bendan Ngisor, Semarang, 50233

Email: pps@unnes.ac.id
}

ISSN 2252-6889 


\section{Pendahuluan}

Di era globalisasi, pengembangan kreativitas merupakan hal yang tidak bisa diabaikan. Persaingan global semakin luas tidak hanya keahlian di bidang kognisi tetapi juga keterampilan hidup menjadi kebutuhan dalam karakter. Maraknya persaingan dalam berbagai bidang baik tingkat regional maupun internasional membuat bangsa indonesia semakin sadar akan pentingnya kreativitas, karena kreativitas sangat dibutuhkan dalam setiap sektor kehidupan. Manusia dituntut untuk mandiri dan kreatif dalam kehidupan.

Kreativitas berpikir merupakan hal vital karena mampu mengarahkan individu menuju cara yang paling ideal untuk mengatasi saat-saat sulit yang dilalui sehingga menjadi manusia yang sanggup belajar, tegar, dan meraih kesuksesan. Kreativitas berpikir menciptakan pribadi yang mampu menyulap impian menjadi realitas (Aluqshari, 2005:30). Dengan kreatif orang akan lebih bisa mengembangkan diri.

Sebagaimana yang diungkapkan Mulyadi, (dalam Munandar 2010: 213) "Kreativitas sungguh mampu meningkatkan kualitas hidup". Orang yang kreatif menggunakan pengetahuan yang dimilikinya dan membuat lompatan yang memungkinkan, mereka memandang segala sesuatu dengan cara-cara yang baru.

Pentingnya pengembangan kreativitas bagi siswa sekolah telah tertulis dalam tujuan Pendidikan Nasional Indonesia dan Peraturan Menteri Pendidikan Nasional nomor 22 tahun 2006 tentang standar isi. Dalam UndangUndang Nomor 20 Tahun 2003 pasal 1 tentang Sistem Pendidikan Nasional disebutkan bahwa, Pendidikan adalah usaha sadar dan terencana untuk mewujudkan suasana belajar dan proses pembelajaran agar peserta didik secara aktif mengembangkan potensi dirinya untuk memiliki kekuatan spiritual keagamaan, pengendalian diri, kepribadian, kecerdasan, akhlak mulia, serta keterampilan yang diperlukan dirinya, masyarakat, bangsa dan negara.

Lebih lanjut pada pasal 3 dinyatakan bahwa tujuan pendidikan nasional adalah untuk mengembangkan potensi peserta didik agar menjadi manusia yang beriman dan bertaqwa kepada Allah SWT, berakhlak mulia, sehat, berilmu, cakap, kreatif, mandiri dan menjadi warga negara yang demokratis serta bertanggung jawab. Berdasarkan tujuan pendidikan nasional di atas disebutkan bahwa salah satu tujuan pendidikan nasional adalah mendidik peserta didik menjadi manusia yang kreatif.
Kreativitas dapat tumbuh dan berkembang pada lingkungan keluarga, masyarakat, maupun lingkungan sekolah. Dalam membentuk kreativitas, sekolah sebagai lembaga pendidikan, memberikan kontribusi besar terhadap perkembangan kreativitas siswa. Namun sangat disayangkan kreativitas sebagai kemampuan untuk melihat kemungkinan-kemungkinan untuk menyelesaikan suatu masalah, merupakan bentuk pemikiran yang sampai saat ini masih kurang mendapat perhatian dalam pendidikan formal. Siswa lebih dituntut untuk berpikir linier, logis, penalaran, ingatan atau pengetahuan yang menuntut jawaban paling tepat terhadap permasalahan yang diberikan, kurang memberikan latihan kemampuan berpikir kreatif (Guilford dalam Munandar, 2009:31).

Hasil penelitian Aziz menyarankan agar pengembangan kreativitas bisa dilakukan secara terintegrasi dalam bidang studi atau bisa juga dilakukan secara terpisah dalam program ekstrakurikuler berupa pelatihan-pelatihan berpikir kreatif atau metode pemecahan masalah secara kreatif, apapun bentuknya yang paling penting adalah kreativitas siswa harus dikembangkan dalam proses pendidikan, sehingga mampu menjawab anggapan bahwa pendidikan di Indonesia kurang mengapresiasi kreativitas (Aziz, 2010:92) .

Berdasarkan observasi di lapangan, wawancara dengan koordinator guru bimbingan konseling (BK), guru BK kelas VIII dan 2 orang siswa SMP N 2 Semarang (13 Oktober 2012), diperoleh informasi bahwa di SMP Negeri 2 Semarang telah melaksanakan layanan bimbingan kelompok. Layanan bimbingan kelompok yang dilaksanakan sudah sesuai dengan standart penyelenggaraan bimbingan kelompok mulai dari identifikasi kebutuhan, proses pelaksanaan, hingga evaluasi. Namun pelaksanaannya masih bersifat umum belum menggunakan teknik dan pendekatan khusus.

Pengembangan kreativitaspun telah menjadi salah satu tujuan yang ingin dicapai melalui layanan bimbingan kelompok. Namun diakui oleh para konselor tersebut bahwa hasilnya belum maksimal, masih terdapat siswa yang belum mengeksplorasi potensi yang dimiliki secara optimal, sehingga memang dirasa perlu untuk melakukan pengembangan lebih lanjut terhadap layanan bimbingan kelompok agar perkembangan kreativitas siswa lebih optimal.

Kaitannya dengan proses pendidikan di sekolah, ini merupakan tugas guru termasuk guru Bimbingan dan Konseling melalui layanan bimbingan dan konseling karena 
sebagaimana disebutkan bahwa salah satu tujuan bimbingan dan konseling adalah membantu mengembangkan potensi siswa secara optimal. Bantuan yang diberikan kepada siswa agar efektif harus mempertimbangkan relevansi antara jenis layanan bimbingan dengan masalah yang dialami oleh siswa. Bantuan yang tepat akan memperoleh perubahan-perubahan tingkah laku yang diharapkan.

Layanan bimbingan kelompok dapat dijadikan salah satu pilihan untuk memberikan bantuan pada siswa. Di dalam bimbingan kelompoksiswadapat membahas topikkreativitas, berdikusi bersama-sama dan melakukan aktivitas kreatif. Bimbingan kelompok dengan teknik mind mapping menjadi pilihan dalam layanan karena mempertimbangkan latar belakang sifat siswa, yaitu menyukai hal-hal yang baru dan menarik.

Dalam perkembangannya usia remaja adalah usia yang penuh dengan imajinasi. Dengan melalui layanan bimbingan kelompok dengan teknik mind mapping masing-masing anggota dapat menyusun dan mengembangkan imajinasinya berupa ide dan gagasan dalam sebuah peta. Bimbingan kelompok dengan teknik mind mapping dapat dipilih sebagai salah satu cara dalam pelaksanaan layanan memiliki keuntungan sebagai alat untuk mengembangkan kreativitas dimana siswa dapat mengaktifkan seluruh otaknya untuk berfikir, fokus pada pokok bahasan, membuat rencana, menyusun dan menjelaskan pikiran-pikiran ke dalam peta.

Selainitujuga mindmapping tidakmemiliki jawabanyangbenaratausalah, bahkanmendorong peserta didik untuk menjadi terbuka dan tidak terikat oleh pembatasan, ini adalah teknik yang berharga untuk membantu meningkatkan tingkat kreativitas dalam pendidikan dan juga mengajar anak-anak bagaimana menjadi kreatif dalam situasi masa depan. Dalam mind mapping, gagasan dan pemikiran dapat mengalir bebas (Wycoff. J, 2005:64).

Berdasarkan uraian latar belakang tersebut, peneliti menganggap penting pengembangan model bimbingan kelompok dengan teknik Mind Mapping untuk mengembangkan kreativitas siswa. Atas dasar hal tersebut peneliti ingin mengembangkan model bimbingan kelompok teknik Mind Mapping untuk mengembangkan kreativitas siswa kelas VIII SMP Negeri 2 Semarang Tahun Ajaran 2012/2013.

Berpijak dari latar belakang masalah di atas, maka permasalahan penelitian ini yaitu Bagaimana model bimbingan kelompok dengan teknik Mind Mapping untuk mengembangkan kreativitas siswa SMP Negeri 2 Semarang.
Tujuan penelitian ini adalah menghasilkan model bimbingan kelompok dengan teknik Mind Mapping yang efektif untuk mengembangkan kreativitas siswa SMP Negeri 2 Semarang.

\section{Metode}

Tujuan akhir dari penelitian ini adalah menghasilkan model bimbingan kelompok dengan teknik Mind Mapping untuk mengembangkan kreativitas siswa SMP Negeri 2 Semarang. Dengan memperhatikan tujuan akhir dari penelitian ini, maka penelitian ini termasuk dalam Research and Development, yaitu "metode penelitian yang digunakan untuk menghasilkan produk tertentu, dan menguji keefektifan produk tersebut" (Sugioyono 2010:407). Metode yang digunakan dalam penelitian ini adalah mixing methods. Menurut Samsudi (2009:93-94) mixing methods merupakan penggabungan antara metode kuantitatif dengan metode kualitatif.

Pengembangan model bimbingan kelompok dengan teknik mind mapping untuk mengembangkan kreativitas siswa mengadopsi 10 tahapan pengembangan menurut Borg \& Gall (dalam Sugiyono 2010:409), langkah-langkah yang seyogyanya ditempuh dalam penelitian pengembangan meliputi: (1) studi pendahuluan, (2) perencanaan, (3) pengembangan model hipotetik, (4) penelaahan model hipotetik, (5) revisi, (6) uji coba terbatas, (7) revisi hasil uji coba, (8) uji coba lebih luas, (9) revisi model akhir, dan (10) diseminasi dan sosialisasi, namun dalam penelitian ini dimodifikasi menjadi enam tahap. Hal ini dilakukan dengan alasan disesuaikan dengan kebutuhan penelitian. Keenam tahapan tersebut adalah sebagai berikut:

Tahap I: Persiapan Pengembangan Model Bimbingan kelompok

Pada tahap ini peneliti melakukan penelitian pendahuluan (studi evaluasi) yaitu mengidentifikasi pemenuhan kebutuhan siswa yang berorientasi pada pengembangan kreativitas, kondisi objektif fasilitas bimbingan dan konseling, implementasi aktual bimbingan kelompok di SMP N 2 Semarang, untuk mendapatkan informasi tentang permasalahan dan kebutuhan siswa akan layanan bimbingan kelompok serta kekurangan dalam implementasi bimbingan kelompok diukur dari layanan bimbingan kelompok yang ideal (konseptual).

Tahap II: Merancang Model Hipotetik Bimbingan kelompok Dengan Teknik Mind Mapping.

Tahap ini merancang model hipotetik berdasarkan kajian studi evaluasi, kajian teoretik, 
kajian hasil penelitian, dan kajian ketentuan formal. Peneliti melakukan analisis kesenjangan antara model hipotetik dengan implementasi aktual di lapangan. Setelah itu kemudian peneliti mendiskripsikan kerangka kerja kolaboratif dalam menguji kelayakan model hipotetik.

Tahap III: Uji kelayakan Model Hipotetik Bimbingan kelompok dengan teknik Mind Mapping.

Tujuan pengujian model bimbingan kelompok dengan teknik mind mapping yaitu untuk menggali informasi dan bahan-bahan pertimbangan dalam merevisi model produk yang dikembangkan serta menentukan manfaat dan kesiapan model diberlakukan di SMP N 2 Semarang. Pengujian model meliputi pengujian komponen, pengujian sub sistem dan pengujian secara keseluruhan dari sistimatisnya model. Komponen-komponen model bimbingan kelompok dengan teknik mind mapping diuji terlebih dahulu, kemudian diuji secara keseluruhan dari sistemnya. Pada tahap ini, model hipotetik bimbingan kelompok dengan teknik mind mapping diuji secara rasional (uji kelayakan) melalui uji ahli, dan uji praktisi yang dilakukan melalui diskusi. (Teruji 1)

Tahap IV: Perbaikan Model Hipotetik

Perbaikan model bimbingan kelompok dengan teknik mind mapping hipotetik. Berdasarkan uji kelayakan diperoleh balikan (feedback) yang diperlukan bagi peyempurnaan model. Perbaikan model dilakukan secara kolaboratif antara peneliti dengan konselor di sekolah. Setelah melalui proses tersebut barulah dapat dihasilkan model bimbingan kelompok dengan teknik mind mapping yang telah teruji tahap I.

Tahap V: Uji-Lapangan (Uji-Empirik) Model Hipotetik

Uji-lapangan (uji-empirik) model bimbingan kelompok dengan teknik mind mapping hipotetik. Uji-lapangan dilakukan melalui penelitian partisipatoris, yaitu dilakukan bersama konselor dalam menyusun rencara kegiatan uji-lapangan, melaksanakan uji lapangan dan mendeskripsikan hasil pelaksanaan uji-lapangan. Uji lapangan dilakukan di SMP N 2 Semarang yang melibatkan melibatkan 3 orang konselor dan 10 siswa (anggota kelompok). Dari hasil terhadap proses pelaksanaan uji-lapangan, diperoleh balikan (feedback) yang diperlukan bagi penyempurnaan model.

Tahap VI: Merancang Model "Akhir" Bimbingan kelompok dengan teknik mind mapping (Teruji II).
Kegiatan tahapini adalah merancang model "akhir" bimbingan kelompokdenganteknikmind mapping. Berdasarkan balikan yang diperoleh melalui uji lapangan (uji-empirik) dilakukan evaluasi hasil uji-lapangan dan perbaikan model secara kolaboratif antara peneliti dan konselor di sekolah. Setelah melalui proses tersebut barulah dapat dihasilkan model bimbingan kelompok dengan teknik mind mapping sebagai model yang telah teruji tahap II.

Subjek uji coba dalam penelitian ini adalah siswa kelas VIII SMP N 2 Semarang sebanyak 10 orang dari populasi yang berjumlah 167 siswa yang dipilih secara purposive sampling. Instrument pengumpulan data yang digunakan dalam penelitian ini adalah wawancara, observasi, studi dokumentasi dan skala kreativitas. Adapun teknikyang digunakan dalam analisis kelayakan model meliputi: a. Uji rasional model dengan melibatkan pakar bimbingan dan konseling; $b$. Uji kepraktisan model dengan melakukan forum group disscution dengan para praktisi atau guru BK di SMP N 2 Semarang.

Metode yang digunakan untuk mengetahui efektifitas model dalam penelitian ini menggunakan metode pre-experimental designs dengan desain one group pre-test and post-test design, yaitu dengan menganalisis kreativitas siswa sebelum dan sesudah mengikuti bimbingan kelompok dalam pengujian lapangan model. Selanjutnya untuk membuktikan hipotesis penelitian berupa pengujian efektivitas model digunakan uji Wilcoxon.

\section{Hasil dan Pembahasan}

Berdasarkan hasil studi pendahuluan diketahui bahwa bimbingan kelompok di SMP $\mathrm{N} 2$ Semarang telah dilaksanakan oleh konselor namun model BKp yang dilaksanakan masih bersifat umum belum menggunakan pendekatan ataupun teknik-teknik khusus. Pelaksanaan program bimbingan kelompok (BKp) di SMP $\mathrm{N} 2$ Semarang 2 kali dalam 1 semester. Fasilitas bimbingan dan konseling SMP $\mathrm{N} 2$ sudah cukup memadai. Implementasi evaluasi dan tindak lanjut sudah dilakukan namun pada pelaksanaannya tidak selalu relevan dengan program yang direncanakan. Dukungan sistem terhadap layanan bimbingan kelompok belum optimal.

Hasil studi tentang kreativitas siswa yang dilakukan pada seluruh kelas VIII dengan responden 167 siswa diperoleh hasil 57\% siswa memiliki tingkat kreativitas sedang, dan $43 \%$ siswa memiliki kreativitas tinggi sedangkan 
kreativitas sangat tinggi, rendah dan sangat rendah $0 \%$.

Bila digambarkan dalam bentuk grafik tingkat kreativitas siswa kelas VIII SMPN 2 Semarang secara umum tampak seperti pada grafik di berikut:

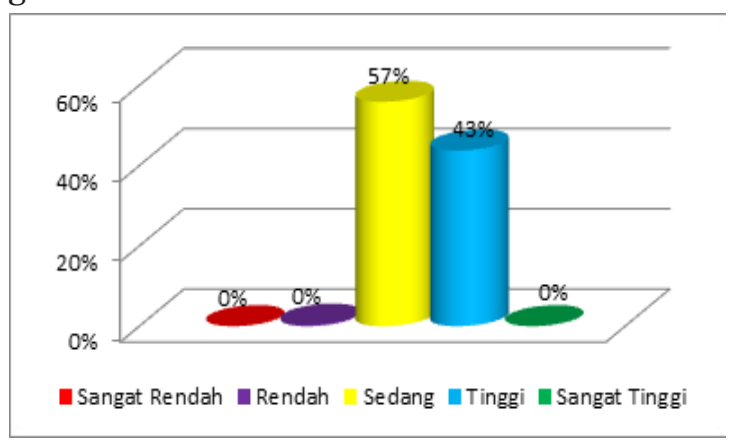

Gambar 1. Tingkat kreativitas siswa kelas VII

Dari grafik tersebut menunjukkan sebagian besar kreativitas siswa sedang, agar potensi kreatif siswa dapat berkembang lebih optimal perlunya upaya pengembangan model layanan bimbingan kelompok yang diharapkan dapat membantu para konselor SMP N 2 semarang dalam mengembangkan kreativitas siswa. Model yang dimaksud adalah model bimbingan kelompok dengan teknik mind mapping untuk mengembangkan kreativitas siswa. Model bimbingan kelompok dengan teknik mind mapping yang dikembangkan dalam penelitian ini dirumuskan dari kerangka kerja yang berlandaskan pada teori bimbingan kelompok secara umum, mind mapping, kreativitas dan karakteristik siswa SMP.

Model Bimbingan Kelompok dengan teknik mind mapping tersusun atas 12 komponen yaitu: (1) Rasional, (2) Konsep Kunci yang terdiri dari (a) Pengertian Bimbingan Kelompok dengan teknik mind mapping, (b) Tujuan Model Bimbingan Kelompok dengan teknik mind mapping (c) Teori dasar pengembangan model: Teknik mind mapping, kreativitas dan karakterisitk siswa SMP (3) Isi Model Bimbingan Kelompok dengan teknik mind mapping (4) Peran Konselor, (5) Fungsi Konselor, (6) Kualifikasi Konselor, (7) Prosedur Kerja Bimbingan Kelompok dengan teknik mind mapping, (8) Anggota Kelompok, (9) Sifat Topik, (10) Suasana Interaksi, (11) Tahap-Tahap pelaksanaan Bimbingan Kelompok dengan teknik mind mapping. Dan komponen model yang terakhir, (12) Monitoring, evaluasi dan tindak lanjut.

Untuk menghasilkan model bimbingan kelompok dengan teknik mind mapping yang teruji secara efektif, maka diperlukan adanya uji kelayakan model. Uji kelayakan model ini dilakukan melalui penilaian pakar bimbingan dan konseling dan penilaian praktisi di lapangan. Kemudian model tersebut di uji cobakan di lapangan sebanyak delapan kali pertemuan.

Berdasarkan hasil penelitian, didapatkan hasil yaitu secara keseluruhan kreativitas siswa meningkat dari rata-rata 218,2 menjadi 245,3, terjadi kenaikan 27,1. Tingkat kreativitas semula $66,1 \%$ menjadi $74,3 \%$, terjadi kenaikan $8,2 \%$. Kemudian diujikan dengan rumus Wilcoxon dengan bantuan perangkat lunak SPSS 16 . Hasil yang diperoleh adalah nilai $Z=-2,814$. Pada uji statistik Asymp. Sig. (2-tailed)/asymptotic significance untuk uji dua sisi tertera angka o,005, oleh karena kasus dalam penelitian ini adalah uji satu sisi, maka probabilitas menjadi 0,0025. Sehingga dapat terlihat bahwa probabilitas dibawah 0,05 $(0,0025<0,05)$ maka dapat dikatakan bimbingan kelompok dengan teknik mind mapping efektif untuk mengembangkan kreativitas siswa.

\section{Simpulan}

Berdasarkan hasil analisis data, mulai dari tahap penelitian pendahuluan hingga tahap uji coba model, dapat disimpulkan bahwa layanan bimbingankelompokdiSMPN2Semarang telah dilaksanakan oleh konselor akan tetapi masih bersifat umum belum menggunakan pendekatan dan teknik khusus.

Hasil penyebaran skala kreativitas pada 167 siswa kelas VIII SMP N 2 Semarang, ditemukan secara umum rata-rata kreativitas siswa berada pada kategori sedang, hal ini berarti sebagian besar siswa SMP N 2 Semarang memerlukan pengembangan kreativitas.

Model bimbingan kelompok dengan teknik mind mapping disusun berdasarkan pada model Bimbingan kelompok secara umum, teori kreativitas, mind mapping dan karakteristik siswa SMP, sehingga memiliki spesifikasi yang berbeda dari model bimbingan kelompokyang sudah ada di sekolah. Model bimbingan kelompok dengan teknik mind mapping, terdiri dari 12 komponen.

Hasil uji model bimbingan kelompok dengan teknik mind mapping terbukti efektif untuk mengembangkan kreativitas siswa. Hal ini terlihat dari perolehan skor pengukuran skala kreativitas meningkat dari kondisi awal sebelum diberi perlakuan bimbingan kelompok dengan teknik mind mapping (pre test) dengan kondisi akhir setelah diberi perlakuan bimbingan kelompok bimbingan kelompok dengan teknik mind mapping (post test). Uji keefektifan model dibuktikan melalui uji statistik non parametris 
wilcoxon.

\section{Ucapan Terimakasih}

Untuk itu pada kesempatan ini penulis ingin menyampaikan terima kasih dan penghargaan yang setinggi-tingginya kepada:

Prof. Dr. Samsudi, M.Pd, Direktur Program Pascasarjana Unnes, yang telah memberikan kesempatan serta arahan selama pendidikan, penelitian dan penulisan tesis ini.

Dr. Anwar Sutoyo, M.Pd, Ketua Program Studi Bimbingan dan Konseling Program Pascasarjana UNNES sekaligus pembimbing II, yang telah memberikan kesempatan dan sabar memberikan bimbingan, arahan sejak permulaan sampai dengan selesainya tesis ini.

Prof. Dr. DYP Sugiharto, M.Pd,.Kons, pembimbing I dalam penulisan tesis ini dan dosen yang dengan yang ditengah-tengah kesibukannya telah memberikan bimbingan yang mendalam dengan sabar dan kritis terhadap permasalahan, selalu memberikan motivasi mulai dari awal sampai akhir.

Bapakdan Ibu dosen Pascasarjana Unnes, yang telah banyak memberikan bimbingan dan ilmu kepada penulis selama menempuh pendidikan .

Drs. Sutomo, A.Md., M.M. Kepala SMP $\mathrm{N} 2$ Semarang yang telah memberikan izin penelitian kepada penulis.

Para Guru BK SMP N 2 Semarang, Ibu Sukati, S.Pd.,Kons, Ibu Enny Setyawati, S.Pd., dan Ibu Dra. Ani Prihartini Judiati, M.Pd. yang telah banyak membantu peneliti selama penelitian.

Semua pihak yang tidak dapat disebutkan namanya satu persatu.

\section{Daftar Pustaka}

Buzan, T. 2004. Mind Map untuk Meningkatkan Kreativitas. Jakarta: PT. Gramedia Pustaka Utama

Cain, M. E. (2001/2002). Using mind maps to raise standards in literacy, improve confidence and encourage positive attitudes towards learning. Study conducted at Newchurch Community Primary School, Warrington. (diunduh 2 Oktober 2012)

Chen, Febe. 2010. Be Creative: Menjadi Pribadi Kreatif. Jakarta: Gramedia Pustaka Utama

DePorter. B, at. all. 2010. Quantum Teaching. Penterjemah: Ary Nilandari. Bandung: Mizan Pustaka

Munandar, U. 2009. Pengembangan Kreativitas Anak Berbakat. Jakarta: Rineka Cipta

Prayitno. 2004. .Layanan Bimbingan dan Konseling Kelompok. (L6 \& L 7). Padang: Jurusan Bimbingan dan Konseling FIP UNP

Riswanto dan Putra, P.P. (2012). The Use of Mind Mapping Strategy in the Teaching of Writing at SMAN 3 Bengkulu, Indonesia. International Journal of Humanities and Social Science Vol.2 No. 21; November 2012 (diunduh 2 Oktober 2012).

Romlah, Tatik. 2006. Teori dan Praktik Bimbingan Kelompok. Malang: Universitas Negeri Malang

Sugiyono. 2011. Metode Penelitian Kombinasi (Mixed Methodes). Bandung: Alfabeta

Wycoff, Joyce. 2005. Menjadi Super Kreatif Melalui Metode Pemetaan Pikiran. Bandung: Kaifa 